\title{
Methodical aspects of the energy industries interconnected operation modeling at the energy security research under modern conditions
}

\author{
Pyatkova Natalya*, Boyarkin Denis \\ Melentiev Energy Systems Institute, 130 Lermontov str., Irkutsk, Russia
}

\begin{abstract}
The relevance and significance of energy security problems studies in modern conditions of energy systems operation, during the period of negative trends growth in the energy sector, is undeniable and concerns two main aspects:

- the need for long-term, deficit-free provision of consumers with the required types of energy resources during the functioning of the energy sector under normal conditions;

- the need to create conditions for providing consumers with energy resources when implementing threats to energy security.

Due to the impossibility of conducting full-scale experiments on operating fuel and energy systems, work related to the modeling of these systems, the development of specialized software and tools, the rational organization of a computational experiment to find ways to provide consumers with energy-free supplies when operating in normal contingency conditions.

The main result presented in the article is a complex of energy systems models that take into account the intellectual nature of modern systems as much as possible and allow conducting energy security studies of the country and regions at a new qualitative level.
\end{abstract}

\section{Introduction}

In modern conditions of the energy systems functioning and development, the relevance and significance of research on energy security problems increases. This is primarily due to high damage and sometimes catastrophic consequences in cases of interruption in the supply of energy resources to consumers. Energy security concerns two aspects:

-the need for long-term deficit-free provision of consumers with the required types of energy resources during the operation of the energy sector under normal conditions;- the need to create conditions for the provision of energy resources to consumers in the conditions of the threats implementation to energy security.

As knowt, the of threats realization to energy security leads to significant damage to the economy of the country and regions. This, for example, a decrease in investment opportunities, which can lead to a decrease in the levels of oil and gas production in the country, to an increase in the share of physically and morally obsolete fixed production assets in the energy sectors, to a slowdown in the rate of decline in the value of the specific energy intensity of GDP, which is currently.

A decrease in investment opportunities in the sectors of the fuel and energy complex is traced for the electric power, gas and coal industries [1-3], namely:

- in the electric power industry, the reduction in investments in 2018 compared to 2011 was $35 \%$;

- investments in the gas industry decreased by more than $40 \%$;

* Corresponding author: nata@,isem.irk.ru
- investments in the coal industry were declining - in 2016 they amounted to $44 \%$ of the 2012 level.

In the event of natural threats, deviations of the maximum seasonal heating loads of the regions, depending on their climatic conditions, from the composition of consumers in them, up to $20-30 \%$ are possible. Also, deviations can be accompanied by a significant increase in the demand for energy resources both for a single climatic zone and for several neighboring regions.

Technogenic threats are most critical for the gas industry and the electric power industry. In the gas supply system, one of the most dangerous factor is the possibility of damage to transcontinental gas pipelines running from a large gas-producing region through the Urals to the European part of Russia []. In the electric power industry, significant undersupply can be caused by breaking ties between individual power systems or emergency situations at specific power plants (for example, an accident at the Sayano-Shushenskaya HPP in 2009, a systemic accident at power facilities in the Northwestern Federal District due to a failure at the Bratsk HPP in June 2017).

As for the oil industry, there is a lag in the reproduction of the oil production raw material base, which is accompanied by a decrease in the oil recovery factor (from $49 \%$ to $30 \%$ and below).

The dominant, in some cases almost monopoly role of natural gas in the boiler and furnace fuel balance in European regions of Russia, which has developed over the past twenty years and is slowly overcome in the future, is 
a serious strategic threat to Russia's energy security. The danger here lies is that such a virtually monostructure makes the economy and population of this region too dependent on the reliability of gas supplies, produced and transported mainly from one gas-producing region and through one pipeline system owned by one company-a monopolist, and besides subject to increased danger of technogenic and natural influences.

In all branches of the fuel and energy complex, the share of equipment that has exhausted its resource (standard service life) is increasing. This is characterized by a high accident rate, significant costs and duration of repairs, low technical level.

To date, about $70 \%$ of the main oil pipelines were over 20 years old, of which about half were in operation for more than 30 years, while, despite the commissioning of new oil pipelines, there has been no qualitative change: the share of worn out equipment remains large. In the gas transportation system at the beginning of 2009 , about $30 \%$ of the pipelines linear part and $10 \%$ of of compressor stations gas pumping units have been in operation for more than 30 years []. The problem of production assets depreciation in the power industry is becoming extremely acute. The total capacity of obsolete equipment at the country's power plants is about $38 \%$ of the installed capacity.

Due to the impossibility of carrying out full-scale experiments on operating energy systems of the fuel and energy complex, research, related to the modeling of these systems, the development of specialized software and tools, the rational organization of a computational experiment to find ways to provide consumers with energy resources without deficiency when operating under normal conditions and in emergency situations are particular importance.

Modern conditions for the development of information technologies, the emergence of high-performance computing facilities, as well as the intellectualization of energy systems and the need for their functioning in a digital economy impose special requirements on the used model computing facilities on the one side. On the other side, they present opportunities to increase the adequacy and correct-ness of modeling real systems, to take into account in the models the processes inertia, the dynamics of the emergency situations development in the models of the fuel and energy complex optimization; take into account nonlinearity for increasing adequacy of the processes representation in energy systems to improve the accuracy of decisions.

This work is an integral part of energy security studies. Similar research and development, and models for these studies are focused mainly on solving the problems of long-term planning of the energy systems in normal operating conditions with a horizon of up to 15-20 years. Similar works carried out in other teams is of a local or regional nature with the study of individual aspects of the problem [4-13]. Comprehensive studies that allow assessing the possibilities of all interconnected energy systems functioning and determining the consequences for energy consumers in the event of emergencies in the work of one industry or several industries have not been carried out at the earlier time.

Studies similar to those carried out by the authors are distinguished by their focus on solving the problems of assessing the behavior of energy systems in the context of the threats implementation to energy security, optimizing the modes of energy systems interrelated operation in emergency situations for reliable energy supply to consumers. Based on the results of the research, it is proposed to form a certain list of measures to ensure the level of energy security at the appropriate level.

\section{Methodology of interconnected modeling of energy systems for solving problems of ensuring energy security.}

To study the energy security problems in modern conditions, it is proposed to develop new and improve (adapt) existing mathematical models and methods of interconnected operation of large energy systems within the framework of a single fuel and energy complex (FEC) in various operating conditions. The use of a new modelinstrumental complex will allow conducting research to assess the possibilities of providing consumers with energy resources under the energy security threats implementation of various nature.

The general scheme of the tasks to be solved when assessing the effect of ES threats on the energy security state is shown in Fig. 1. 


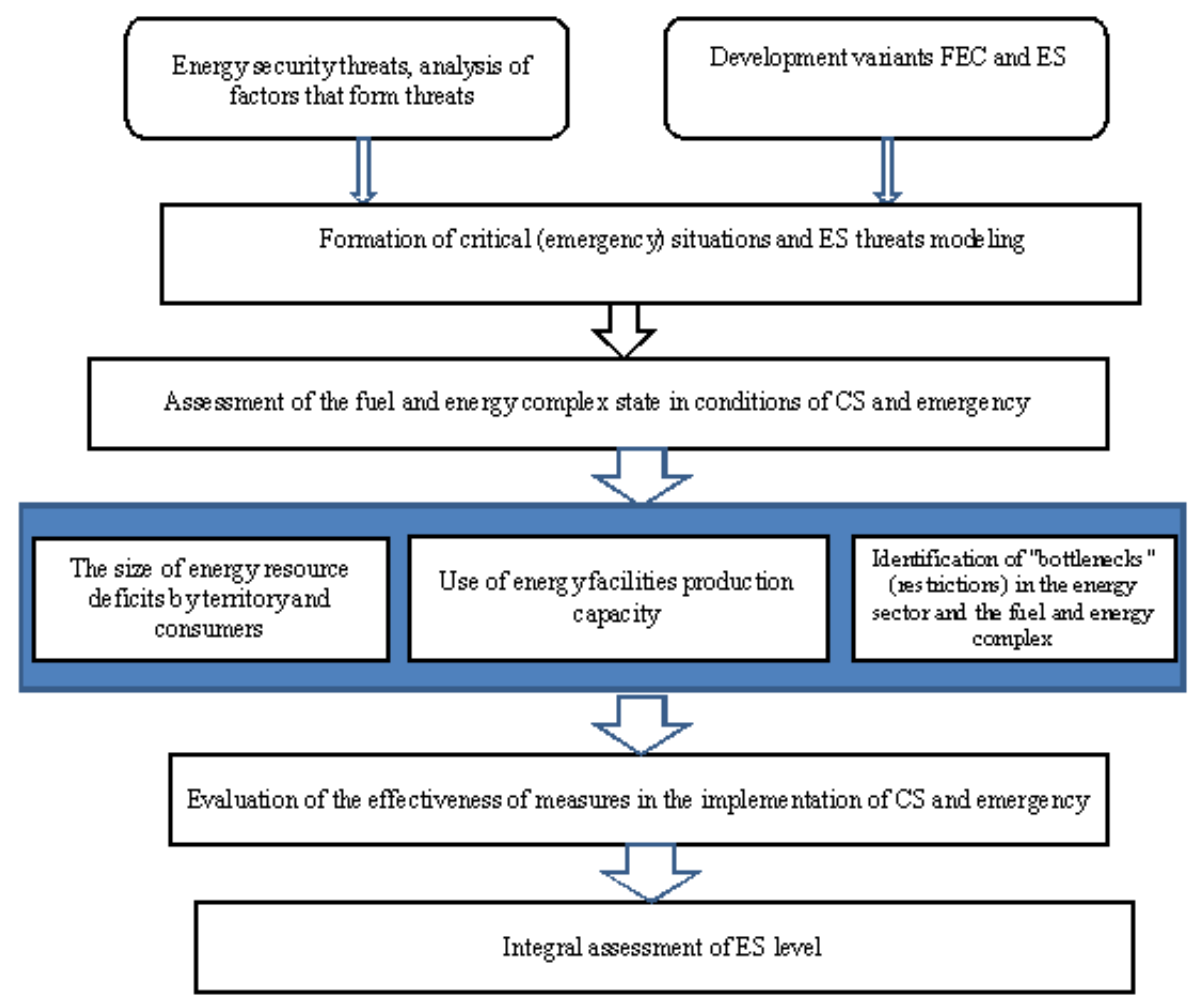

Fig. 1. General scheme of research on ES problems

The initial basis for research is the technical and economic characteristics of energy facilities and reporting data on the state of energy systems, the results of research on the development of the fuel and energy complex, justifying the choice of a long-term strategy and the formation of an energy policy. Based on the socio-economic development program of the country's economy adopted for the future, which determines the demand for fuel and energy resources, an analysis and assessment of energy consumption levels is carried out, taking into account energy conservation.

On the basis of the above characteristics and analysis of ES threats, design conditions are formed for a computational experiment, which is carried out using models of energy systems.

\section{Models of energy systems}

Models of energy systems represent a system of economic and mathematical models for assessing the territorial and production structure of the fuel and energy complex, taking into account the requirements of energy security [15]. These models can be used in two modes:

- in the mode of determining the energy technologies optimal development (taking into account the structural redundancy in the form of capacity reserves, fuel reserves, interchangeability of energy resources) and the optimal distribution of consumed energy resources,

- in the mode of determining the energy resources underdelivery (FER deficits) in the country as a whole and in individual regions.

The structure of the fuel and energy complex models is shown in Fig. 2. Technologically, it consists of the energy complex sectoral subsystems (gas, coal, oil refining (in terms of fuel oil supply) industries, electricity and heat power engineering) and a block of consumers (energy consumption at various types of power plants and boiler houses for generating electricity and heat, other consumers and export consumers are highlighted separately) 


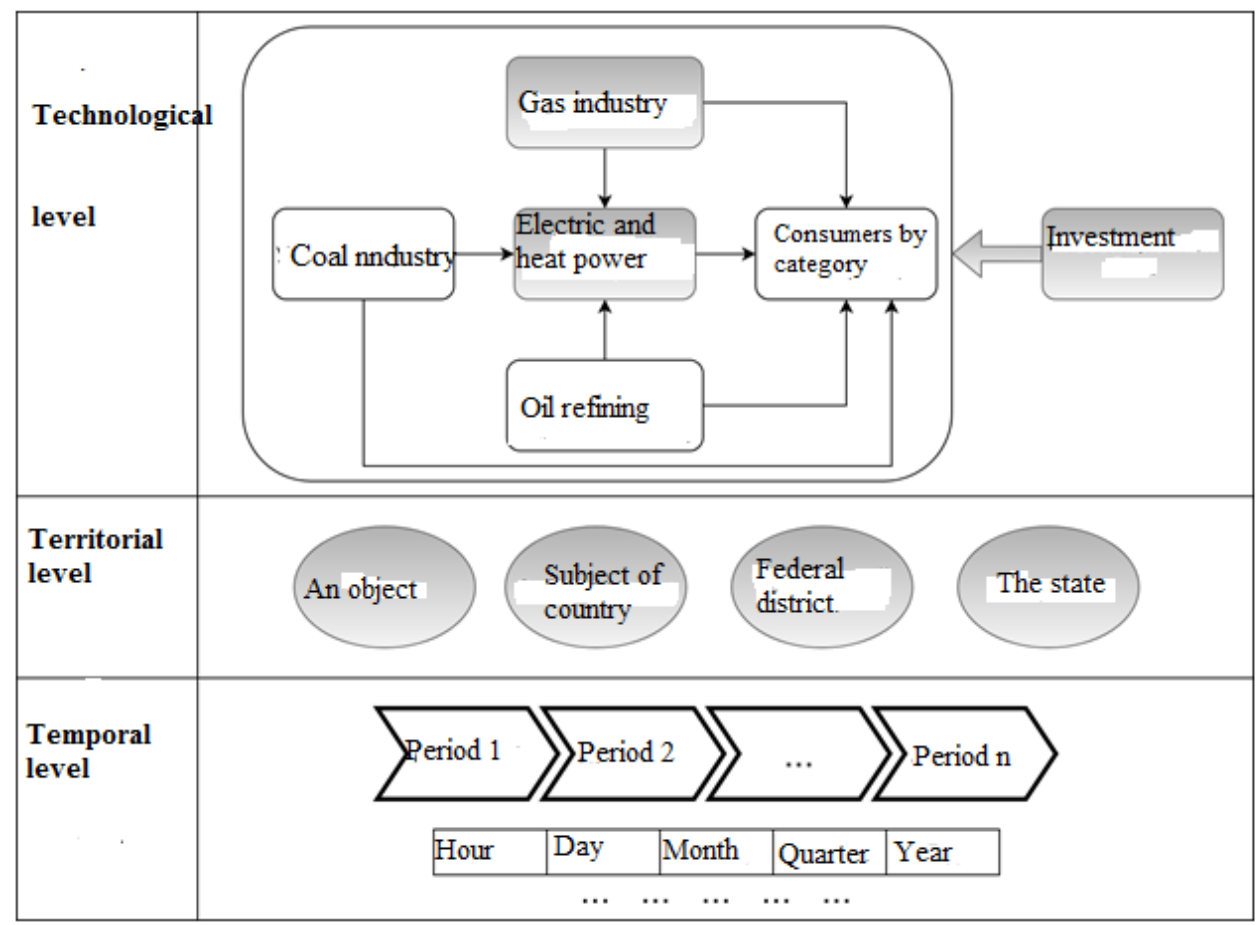

Fig. 2. Territorial, temporal and technological structure of models

The final implementation includes a financial block that describes the investment costs of reconstruction, modernization of existing facilities, obsolete equipment removal, commissioning of new facilities at energy facilities. The development dynamics were also taken into account, which made it possible to track such features of the multi-step process of the fuel and energy complex development as:

- commissioning of new production facilities;

- dismantling and conservation of old objects,

- reconstruction of facilities with a change in the technological scheme.

The dynamics are taken into account in the form of $T$ independent static blocks, each of which describes all the territorial and technological connections of the fuel and energy complex in relation to stage $t$ of the billing period. Dynamic connections between the blocks are built using equations that formulate for all $x_{i}$ objects of the fuel and energy complex the condition for the continuity of their performance at different stages of the billing period. For the first stage, this condition is written as:

$$
x_{i 1}^{o}+x_{i 1}^{c}+x_{i 1}^{d}=P_{i 0},
$$

and for subsequent stages in the form of equations

$$
x_{i t-1}^{o}+x_{i t-1}^{c}+x_{i t-1}^{n}=x_{i t}^{o}+x_{i t}^{c}+x_{i t}^{d},
$$

where $P_{i 0}$ - the technology productivity (object $i$ ) by the beginning of the billing period,

$x_{i t-1}^{n}$ - the performance of the technology new part (object i) at stage $t-1$,

$x_{i t}^{o}$ - the performance of the technology acting part (object $i$ ) at stage $t$, $x_{i t}^{c}$ - conservation of a object part $i$ at stage $t$,

$x_{i t}^{d}$ - liquidation of a object part $i$ на этапе $t$.

For the convenience of forming bonds, equation (2) is divided into two parts

$$
\begin{aligned}
& -x_{i t-1}^{o}-x_{i t-1}^{c}-x_{i t-1}^{n}+Z_{i t-1}=0 \\
& -Z_{i t-1}+x_{i t}^{o}+x_{i t}^{c}+x_{i t}^{d}=0,
\end{aligned}
$$

where $Z_{i t-1}$ - an intermediate variable characterizing the total productivity of object $i$ at the beginning of stage $t$. It takes into account the removal of capacities at stage $t$ and the introduction of new capacities at time stage $t+1$.

In general, these models are used to determine the following characteristics (indicators):

-the size of undersupply (deficit) in energy resources certain types for the considered categories of consumers, allocated territorial associations and the country as a whole, as the magnitude of the discrepancy between a given demand and the possibility of producing this type of energy resource (taking into account reserves, the possibilities of replacing this type of energy resource with others consumers, etc.);

- changes in the throughput of transport links, determined by comparing the corresponding indicators of the considered option with the original;

- rational use of energy facilities production capacities, as well as the distribution of energy resources certain types for the selected categories of consumers.

The main the models in the proposed implementation of the model-instrumental complex are the models of the gas industry and the power industry, the mathematical description of which is presented in the next section. 


\section{Mathematical description of models of the gas and electric power industries}

The flow distribution model in the unified gas supply system (UGSS) is intended to assess the production capabilities of the UGSS during different disturbances. The aims of such studies is to minimize gas deficits at consumption nodes. The gas industry in the model is presented as a combination of three subsystems: gas sources, trunk transport network and consumers [16]. When solving the problem of network state estimation after a disturbance, the optimality criterion for the flow distribution is the minimum gas deficit for consumer with the minimum cost of gas delivery to consumers. This problem can be solved by finding the maximum network flow. The maximum flow problem is formulated as follows [16]:

$$
f \rightarrow \max ,
$$

under the conditions that

$$
\sum_{i \in N_{j}^{+}} x_{i j}-\sum_{i \in N_{j}^{-}} x_{j i}=\left\{\begin{array}{c}
-f, j=O \\
0, j \neq O, S \\
f, j=S
\end{array}\right.
$$

$$
0 \leq x_{i j} \leq d_{i j} \text {, для всех }(i, j) .
$$

In this case, $f$ is the maximized variable corresponding to the maximum flow.

When working with complex schemes, there may be several solutions, that is, several possible maximum flows. Then it is advisable to talk about minimizing the cost of delivering gas to consumers and using the Basaker-Gowen algorithm:

$$
\begin{aligned}
& \sum_{(i, j)} C_{i j} x_{i j} \rightarrow \min , \\
& x \in X^{*},
\end{aligned}
$$

Its application makes it possible to determine the maximum gas flow at its minimum cost or the optimal volumes of daily gas withdrawal from underground gas storage facilities (UGS), which maximally ensure the specified volumes of gas supply to consumers at minimum costs for production, transportation of gas and its extraction from UGS.

Here $O$ is the total source; $S$ is the total sink; $N^{+}{ }_{j}$ is a subset of arcs "incoming" in node $j ; N_{j}^{-}$is a subset of "outgoing" arcs from node $j ; f$ is the value of the cumulative flow in the network; $x_{i j}$ is the flow in an $\operatorname{arc}(i, j) ; d_{i j}$ - limitations on the flow in the arc $(i, j) ; X^{*}$ - the set of solutions to problem (4) - (6); $C_{i j}$ - price or specific costs of gas transportation.

Node $O$ is connected by fictitious arcs with all real sources of energy resources, and node $S$ - with all consumers.

In the UGSS flow distribution model, the Basaker-Gowan algorithm is used to calculate the maximum flow of the minimum cost, which, as a result, makes it possible to determine the possible level of consumer satisfaction with gas. As a result of the implementation of various abnormal situations, it is possible for consumers to have a gas shortage caused by a lack of carrying capacity in certain sections of gas pipelines. Bypassing such narrow or limiting the production capabilities of the system places, in acceptable volumes, will allow reduce the gas shortage among consumers that has arisen in the situation under consideration.

In the case of a gas deficit for consumers, caused by a transmission capacity decreasing of the corresponding gas pipelines, other branches of the main gas pipelines that are not affected by the violation in question can increase gas throughput volumes. In such a situation, the network congestion changes and a transmission capacity decreasing in other sections of the main gas pipelines is possible.

Subsequent clearing of bottlenecks in the GTS will allow minimizing gas deficits for consumers and makes the assessment and identification of possible critical combinations of gas facilities as adequate as possible.

\section{Electric power system model}

As already shown, the EES model is the central link at the fuel and energy complex modeling. The purpose of EPS modeling is to determine the power capacity shortage and undersupply of electricity to consumers as a result of accidents at the fuel and energy complex. For correct modeling of emergency situations, an adequate mathematical model of the EPS is required. The problem to be solved can be formulated as follows: for a known structure, parameters of elements and a capacity consumption graph of a the EPS, it is necessary to determine the power deficit and shortage of electricity for the period from the beginning of an emergency to it's completely eliminated. The computational model of the EPS is a graph of which nodes are energy zones, and arcs are inter-zone connections. The energy zone includes a part of the energy system, as a rule, it is a regional energy system that contains a set of generating units and is characterized by power consumption in every hour of the settlement period. Inter-zone communication includes power lines that connect two energy zones. Thus, for each hour of the calculation period, it is necessary to solve the following problem [17]:

need to find:

$\sum_{i=1}^{I}\left(\bar{N}_{\text {потр }, i}-N_{\text {потр }, i}\right) \rightarrow \min$,

given balance sheet constraints

$N_{\text {ген }, i}-N_{\text {потр }, i}+\sum_{j=1}^{J}\left(1-z_{j i} a_{j i}\right) z_{j i}-\sum_{j=1}^{J} z_{i j}=$

$0, i=1, \ldots, I, i \neq j$,

and linear constraints-inequalities on variables

$$
\begin{aligned}
0 \leq & N_{\text {потр }, i} \leq \bar{N}_{\text {потр }, i}, i=1, \ldots, I, \\
& 0 \leq N_{\text {ген }, i} \leq \bar{N}_{\text {ген }, i}, i=1, \ldots, I, \\
& 0 \leq z_{j i} \leq \bar{z}_{j i}, 0 \leq z_{i j} \leq \bar{z}_{i j}, j=1, \ldots, J, i=
\end{aligned}
$$

$1, \ldots, I, i \neq j$,

where $\bar{N}_{\text {потр, } i}$ is the amount of capacity consumption in the energy zone $i, \mathrm{MW} ; N_{\text {потр, } i^{-}}$ensured capacity consumption in energy zone $i, \mathrm{MW} ; \bar{N}_{\text {ген }, i}$ is the available generating capacity in energy zone $i, \mathrm{MW} ; N_{\text {ген, } i}$ - used generating capacity in the zone of reliability $i, \mathrm{MW} ; \bar{z}_{j i}$, $\bar{z}_{i j}$ - inter-zone communication throughput, MW; $z_{j i}, z_{i j}$ - 
actual load of inter-zone communication, MW; $I=J$ number of energy zones.

\section{New opportunities in energy security research}

The proposed model-instrumental complex, consisting of industry models connected by information flows and an integrating the fuel and energy complex model as a whole, developed for the energy security research will improve the existing practice of assessing the implementation of energy security threats in the following directions:

-to determine the mutual influence of energy systems on each other and to give a comprehensive assessment of the threats impact to energy security;

- will allow taking into account the dynamics of the emergency situations development in the optimization models of energy systems and the fuel and energy complex;

- will allow to keep track of the power consumption schedule, which imposes requirements on industry systems from consumers;

- will allow to take into account nonlinearity for the adequacy of the representation of processes in energy systems to improve the accuracy of decisions made (in models of industry systems)

- take into account natural factors in terms of the impact on the operation of renewable energy sources (periods of low water for hydroelectric power plants, cloudy days for solar power plants, low wind periods for wind farms);

- take into account the influence of inertia in the gas, coal, oil refining industries on the development of emergency situations and link with their development in the power industry, which is key for the fuel and energy complex.

- take into account the peculiarities of the mutual influence of the gas and electric power industries when fulfilling the conditions for the reliability of gas and electricity supply to the production facilities of these industries;

- take into account the peculiarities of the mutual influence of the oil and oil refining and electric power industries when meeting the conditions for the reliability of the supply of electricity and oil products to the production facilities of these industries.

\section{Conclusion.}

The paper presents the methodological features of modeling the interconnected work of industries in modern conditions and an approach to creating a specialized software and instrumental complex that combines models of industry energy systems and the fuel and energy complex model integrating them. The complex being developed is intended for experimental research to find ways of supplying consumers with energy resources without deficits while operating under normal conditions and in emergency conditions. A more detailed representation of energy objects in models will improve the correctness and adequacy of the simulated systems. The proposed complex of models of energy systems will allow taking into account the intellectual nature of modern systems as much as possible and will allow conducting research on the energy security of the country and regions at a new qualitative level.

\section{- Acknowledgment}

This work was carried out with the financial support of the RFBR grant No. 20-08-00367

\section{Literature}

1. Results of the work of the Ministry of Energy of Russia and the main results of the functioning of the fuel and energy complex in 2018 Objectives for the medium term https://minenergo.gov.ru/prezentaciya_kollegiya 2019.pdf

2. The results of the work of the Ministry of Energy of Russia and the main results of the functioning of the fuel and energy complex in 2012-2017. https://www.google.com/url?sa $=t \& r c t=j \& q=\&$ esrc $=$ s\&so urce $=$ web \&cd $=\&$ cad $=$ rja\&uact $=8 \&$ ved $=2$ ahUKEwjJmr3 sjv7qAhUIrosKHYYLB0QQFjAAegQIARAB\&url=http s $\% 3 \mathrm{~A} \% 2 \mathrm{~F} \% 2 \mathrm{Fminenergo.gov.ru} \% 2 \mathrm{Fsystem} \% 2 \mathrm{Fdownlo}$ ad-

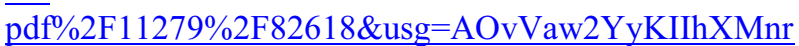
veH YmwJpu2

3. Elena Vavina. 09.12.2019 Vedomosti https://www.vedomosti.ru/business/articles/2019/12/10/818261-20-elektroenergetiki

4. Kozlov MV, Malashenko Yu. E., Nazarova IA, Novikova NM. Izv. RAS. Theory and control systems. 2017. - No. 6.- P. 50-73.

5. Malashenko Yu. E., Nazarova I.A., Novikova N.M. Izv. RAS. Theory and control systems. - 2018. - No. 2. P. 39-51.

6. Malashenko Yu. E., Nazarova I. A., Novikova N.M. Informatics and its applications. - 2017. - T. 11. - Issue. 4. - S. 47-54.

7. 7. Malashenko Yu. E., Nazarova I. A., Novikova N.M. Informatics and its applications. - 2018. - T. 12. Issue. 1. - S. 11-17.

8. 8. Grebenyuk G.G., Nikishov S.M. Control sciences. - 2016. - No. 4. - S. 52-57.

9. Seebregts, Ad J., Goldstein, Gary A., Smekens, Koen. Energy/Environmental Modeling with the MARKAL Family of Models [Электронный pecypc] // Proc. Int. Conf. on Operations Research (OR 2001), Energy and Environment Session, September 3-5, 2001, Duisburg, Germany. Систем. требования: Adobe Acrobat Reader. URL: ftp://ftp.ecn.nl/pub/www/library/report/2001/rx01039.pdf (дата обращения: 22.04.2013).

10. MARKAL [Электронный ресурс] // IEA-ETSAP: The Energy Technology Systems Analysis Programme (ETSAP). 2011. URL: http://www.ieaetsap.org/web/Markal.asp (дата обращения: 22.04.2013).

11. MESSAGE (Model for Energy Supply Strategy Alternatives and their General Environmental Impact) [Электронный ресурс] // International Institute for Applied Systems Analysis (IIASA) [Laxenburg, Austria]. URL: 
http://www.iiasa.ac.at/web/home/research/researchProgr ams/Energy/MESSAGE.en.html (дата обращения: 22.04.2013).

12. E. V. Fedorova, T. G. Zorina Yadernaya energetika. - 2004. - No. 4.

13. The National Energy Modeling System: An Overview 2009 [электронный ресурс] - Режим доступа: http://www.eia.doe.gov/oiaf/aeo/overview/index.html (дата обращения: 22.04.2013).

14. Energy Research Institute of the Russian Academy of Sciences is 25 years old - M . ERI RAN, 2010 .-- 160 p.

15. Pyatkova N.I., Senderov S.M., Pyatkova E.V. Izvestiya RAN. Energy.- 2014.- No. 2. - P.81-87

16. S.M. Senderov, S.V. Vorobev, Reliability Engineering and System Safety (2020). https://doi.org/10.1016/j.ress.2020.107046

17. Reliability of Power Systems // Kovalev G.F., Lebedeva L.M.- New York: Springer, 2019. - 237 p. 